\title{
LA UNIÓN EUROPEA EN EL MARCO CONSTITUCIONAL DE LOS ESTADOS MIEMBROS: EL CASO DE ITALIA*
}

\author{
Diana-Urania GaLETTA \\ Catedrática de Derecho Administrativo \\ Università degli Studi di Milano \\ diana.galetta@unimi.it
}

\section{LOS ORÍGENES DE LA JURISPRUDENCIA CONSTITUCIONAL SOBRE LOS CONTRA LIMITACIONES (CONTROLIMITI)}

El posicionamiento del Tribunal Constitucional acerca de la exigencia de proteger los principios y derechos fundamentales del ordenamiento nacional en relación con la Unión Europea se remonta a una sentencia del 1965 (n. 98 de 27 de diciembre de 1965), en la cual se disputa a las atribuciones jurisdiccionales del Tribunal de Justicia de la Comunidad Europea. Fue cuestionada, de hecho, la compatibilidad con la Constitución de la ley que había hecho ejecutivo en Italia el Tratado CECA, en la parte en la que ésa tenía el efecto de garantizar al juez comunitario una jurisdicción exclusiva sobre los recursos opuestos a las medidas de la alta autoridad comunitaria. Se asumía, específicamente, el contraste de tales normas con una serie de principios fundamentales del ordenamiento constitucional italiano, entre ellos la atribución de la función jurisdiccional a magistrados ordinarios instituidos y regulados por las normas del ordenamiento judicial, la prohibición de institución de jueces extraordinarios y de jueces especiales, y la garantía a cada ciudadano de la completa tutela de derechos y e intereses legítimos contra los actos de la Administración Pública. En ese punto, el Tribunal Constitucional había admitido, sin embargo, que, aunque en ámbito jurisdiccional pueden ser atribuidas a la Comunidad competencias previamente asignadas al Estado, siempre que lo haga, «sin perjuicio del derecho del singulo a la tutela jurisdiccional, [en cuanto] este derecho es

\footnotetext{
* Intervención en la Cátedra Jean Monnet del profesor Ricardo Alonso García, Seminario García de Enterría, Facultad de Derecho de la Universidad Complutense, 24 de abril de 2013.
} 
entre aquellos inviolables del hombre, que la Constitución garantice en el art. 2 Cost.» ( $\$ 2$ de las Consideraciones en derecho).

La referencia a la existencia de un núcleo de normas constitucionales italianas resistentes, sin embargo, a las normas comunitarias viene después desarrollado en la sentencia Frontini (n. 183 de 1973). En ésta, el Tribunal Constitucional italiano observa, de hecho, que «con base en el art. 11 de la Constitución fueron consentidas limitaciones de soberanía únicamente para el logro de las finalidades de allí; y debe entonces excluirse que tales limitaciones [...] puedan de todas formas implicar para los órganos de la CEE un inadmisible poder de violar los principios fundamentales de nuestro ordenamiento constitucional, o los derechos inalienables de la persona humana». Si esto ocurriera, «siempre estaría asegurada la garantía del control jurisdiccional de esta Corte sobre la continua compatibilidad del Tratado con los referidos principios fundamentales» ( $\$ 9$ de las Consideraciones en derecho).

Esta reserva a la apertura del ordenamiento italiano a aquello comunitario se confirma de manera literal en la siguiente sentencia, Granital (n. 170 de 1984) y también en las sentencias n. 1146 de 1988 y n. 203 de 1989.

\section{LOS CONTROLIMITI, DE LA SENTENCIA GRANITAL HASTA LA CARTA DE NIZZA}

La célebre sentencia Granital (n. 170 de 8 de junio de 1984) ha realizado una difícil obra de mediación entre dos opciones (aquella monista del Tribunal de Justicia y aquella dualista del Tribunal Constitucional) aparentemente inconciliables.

De hecho, el Tribunal Constitucional no renunciaba a la premisa de fondo de la separación entre ordenamiento comunitario y nacional, en cuanto ésta definía los dos sistemas como «autónomos y distintos bien que coordinados, según la repartición de competencia establecida y garantizada del Tratado». Pero el Tribunal Constitucional concentra toda su argumentación en la necesidad de identificar la norma aplicable al caso concreto. De hecho, para el Tribunal, una vez que partan de la premisa del efecto directo de las normas comunitarias, el conflicto entre norma comunitaria y norma nacional ni siquiera hubiera podido plantearse como hipótesis, siendo una sola (con base en el sistema del reparto de las competencias) la norma en grado de disciplinar la relación y, por lo tanto, en el caso de especie, la norma comunitaria. La inaplicabilidad de la norma nacional a la 
disputa hacía, entonces, inadmisible, por defecto de relevancia, la cuestión de constitucionalidad. Por otra parte, sin embargo, el Tribunal Constitucional afirmaba que la presencia de una norma comunitaria directamente aplicable no podía determinar la invalidez de la contrastante norma nacional. En cuanto al estatus de aquellas normas nacionales en contraste con disposiciones de la Unión Europea que presenten las características necesarias para poder ser consideradas de efecto directo, según la reconstrucción constantemente propuesta por nuestro Tribunal Constitucional, éstas permanecerían válidas y vigentes pero serían, sin embargo, «no aplicables» hasta que - y sólo en la medida en la cual— la disciplina normativa de la materia sea de competencia del ordenamiento de la Unión Europea (Corte Const., sentencia n. 168 de 1991).

$\mathrm{El}$ acuerdo entre los Tribunales estaba, de hecho, realizado, en nombre de la autonomía/separación de los ordenamientos aún entre ellos coordinados, y la referencia a la existencia de controlimiti (retomando la jurisprudencia Frontini) parecía salvaguardia suficiente de las razones de la soberanía nacional.

Bien es cierto que algunos años más tarde, recurriendo de nuevo a los controlimiti, el Tribunal Constitucional italiano, con la importante sentencia Fragd (n. 232 de 1989), no dudaba en lanzar una advertencia bien precisa al juez comunitario. De hecho, aun pronunciando la inadmisibilidad de la cuestión de constitucionalidad a él propuesta, ésta no dejó de afirmar que una completa retroactividad de las decisiones incidentales declarativas de la invalidez de un reglamento comunitario sería incompatible con el derecho inviolable a la tutela jurisdiccional y, por lo tanto, inconstitucional, siendo admisible, sólo, una limitación de los efectos temporales de tales pronunciamientos.

Entonces el Tribunal Constitucional lograba plantear (aunque sea nivel teórico) una posible intervención suya - a través del control sobre la ley de ejecución del Tratado CEE— sobre normas contenidas en el Tratado que resultarían lesivas de derechos inviolables (en particular los arts. 189 y 177, numeración antigua, Tratado CEE).

Las consecuencias políticas, incluso antes que jurídicas, de las afirmaciones de principio (en realidad nunca aplicadas) contenidas en la sentencia eran evidentes. Sin embargo, en casi veinticinco años pasados de la sentencia n. 232 de 1989, los controlimiti han continuado sin encontrar una aplicación concreta en la jurisprudencia constitucional, no obstante reiteradas enunciaciones conformes a lo anterior en el plano teórico. Y si el debate sobre los controlimiti ha resurgido con vigor recientemente, des- 
pués de la aprobación de la Carta de Niza, ello ha tenido lugar en términos negativos. Muchos comentaristas, de hecho, han empezado a preguntarse sobre el sentido que tendría continuar afirmando la existencia de los controlimiti en un momento en que también la Unión Europea había reconocido formalmente una tutela propia de los derechos fundamentales. Y, en efecto, en un contexto de progresiva apertura del Tribunal de Justicia comunitario a la tutela de los derechos del hombre, es fácil comprender el escepticismo madurado en la doctrina acerca del instituto de los controlimiti y la tentación de abandonar de una vez por todas este elemento en las relaciones entre Estado miembro y Unión Europea.

\section{LA APERTURA DE UN DIÁLOGO DIRECTO CON EL TRIBUNAL DE JUSTICIA: EL PRIMER REENVÍO PREJUDICIAL DEL TRIBUNAL CONSTITUCIONAL ITALIANO}

En 2008, el Tribunal Constitucional italiano abrió una vía al diálogo directo con el Tribunal de Justicia, operando, así, su primer reenvío prejudicial.

La historia es conocida. A raíz de una apelación promovida por el Estado contra una ley de la Sardeña (Ley Regional 4/2006) que había introducido algunos impuestos regionales sólo a cargo de los no residentes en Sardeña (el llamado impuesto sobre lujo), después de haber resuelto (con sentencia n. 102 de 2008) la mayor parte de las cuestiones - incluso las que tienen diferentes perfiles de ilegalidad «comunitaria»-, el Tribunal Constitucional decidió suspender el juicio y operar un reenvío prejudicial al Tribunal de Justicia comunitario, sólo en relación con los impuestos sobre la escala de los aeromuebles y unidades marítimas, para verificar si éstos eran lesivos del principio de libre circulación de los servicios o de la prohibición de ayudas del Estado consagradas a nivel comunitario (orden n. 103 de 2008).

Ha sido ésta, sin duda, una decisión histórica del Tribunal Constitucional italiano, que la doctrina mayoritaria ha individuado como el inicio de una nueva fase en el camino comunitario del Tribunal Constitucional. De hecho en el pasado no sólo se había abstenido de hacerlo de manera rigurosa, sino que hasta había excluido el poseer aquellas connotaciones de «jurisdicción nacional» que el Tratado comunitario requiere a tal condición para poder operar un reenvío prejudicial al Tribunal de Justi- 
cia. No hace muchos años, el Tribunal Constitucional parecía, de hecho, haber cerrado definitivamente la cuestión afirmando, con letra clara, que «en el Tribunal Constitucional no es aparente aquella "jurisdicción nacional" a la cual hace referencia el art. 177 CE [ahora art. 267 TFUE], ya que ésta no puede estar incluida entre los órganos judiciales, ya sean ordinarios o especiales, ya que son muchas y profundas las diferencias entre la tarea encomendada a la primera [...] y aquellas bien advertidas e históricamente consolidadas propias de los órganos jurisdiccionales» (Corte cost., orden n. 536 de 1995). Por esta razón la orden n. 103 de 2008 puede considerarse, en ciertos aspectos, verdaderamente revolucionaria, cuanto más por el hecho que afirma - en evidente antítesis con cuanto ha afirmado del mismo Tribunal Constitucional en 1995- que «el Tribunal Constitucional, aun en la peculiar posición de supremo órgano de garantía nacional a los sentidos del art. 234 CE [ahora art. 267 TFUE], es una jurisdicción nacional y, en particular, una jurisdicción de última instancia», con consiguiente legitimación a levantar reenvío prejudicial.

Sin redimensionar el sentido histórico de esta decisión, el hecho es que la cuestión ha sido levantada en el ámbito de una disputa instaurada ex art. 127 Cost., o sea, en un juicio «en vía principal», en el cual el Tribunal Constitucional es el único órgano jurisdiccional en grado de poder sostener la cuestión ${ }^{1}$. De todas maneras, lo que realmente importa es que el Tribunal Constitucional, a través de este primer reenvío prejudicial suyo, ha abierto de hecho el diálogo directo con el Tribunal de Justicia.

\section{CONTROLIMITI Y JUEZ COMÚN: DEL ASUNTO FEDERFARMA A LA ACTUALIDAD}

El tema de los controlimiti no ha permanecido confinado al ámbito de la jurisprudencia del Tribunal Constitucional. Ha sido abordado también en repetidas ocasiones por el juez común, quien, varias veces, ha intentado aplicar al caso concreto lo afirmado y reafirmado - pero siempre y sólo a nivel teórico- por el Tribunal Constitucional desde la sentencia Frontini en ade-

${ }^{1}$ En lo que respecta al juicio de constitucionalidad en vía incidental, con una orden de 3 de julio de 2013 la Corte Constitucional ha abierto la vía a su petición directa de una decisión prejudicial al Tribunal de Justicia, incluso para aquellos casos en que el Tribunal Constitucional decide también en el contexto de una decisión prejudicial. En consecuencia, no está confirmado el implante originario, que veía en el juez común el promotor necesario del reenvío al Tribunal de Justicia en este caso. 
lante. Y, así, ha ido consolidando de este modo la idea de que es posible un control difuso (generalizado) de los controlimiti por el juez común.

El caso más notorio es, ciertamente, el representado por la sentencia Federfarma del Consejo de Estado (n. 4207 de 8 de agosto 2005), en la cual el Consejo opera una aplicación en concreto (la primera) de la teoría de los controlimiti, negándose a operar un reenvío prejudicial al Tribunal de Justicia comunitario.

En resumen, el razonamiento del Consejo de Estado en la sentencia Federfarma consiste en decir que, dado que la norma nacional controvertida tiene como objetivo proteger el derecho fundamental de la protección de la salud, es del todo inútil operar un reenvío prejudicial al Tribunal de Justicia desde el momento en que no sería en cada caso posible tener en cuenta su decisión.

El Tribunal Constitucional ha reaccionado inmediatamente a esta decisión del Consejo de Estado, a través de una orden de 2006 (n. 454 de 28 diciembre) con la cual ha excluido expresamente la posibilidad de una aplicación generalizada de los controlimiti por parte del juez común y ha reiterado que, donde exista una duda como aquella que había surgido en el caso Federfarma, el juez común debería operar un reenvío prejudicial al Tribunal Constitucional. De hecho, sólo al Tribunal Constitucional correspondería juzgar la diferencia entre la norma del Derecho comunitario y los derechos inalienables de la persona humana o los principios fundamentales de nuestro ordenamiento constitucional.

No obstante la toma de posición clara del Tribunal Constitucional, evidentemente contraria a la idea de una aplicación difusa/generalizada de los controlimiti, existen ejemplos de aplicación de éstos por parte de los jueces comunes. En particular vale la pena señalar aquí estos dos casos:

a) La sentencia n. 16542 de 2006, de casación penal (sucesivamente superada por las Secciones Unidas con sentencia n. 4614 de 2007). Con esta decisión el juez común, aunque no refiriéndose expresamente a la teoría de los controlimiti, se niega a elevar la cuestión de legitimidad comunitaria (y constitucional) de una norma de ley nacional que prohibía la entrega de un individuo después de un mandato de captura europeo en un caso no previsto de la decisiónmarco. La razón es que tal norma «reproduce una norma constitucional (art. 13 Cost., último párrafo)», que evidentemente prevalece sobre el Derecho de la Unión. De esta manera, el Tribunal de Casación se ha arrogado la función de decidir por sí mismo si 
la legislación nacional en materia de prisión preventiva, interpretada a la luz de los controlimiti, constituye un principio fundamental del ordenamiento jurídico, en lugar de limitarse a asumir una duda sobre la cuestión, conducente a la activación del incidente de legitimidad constitucional.

b) Por el contrario, en el asunto de la recuperación de ayudas del Estado juzgadas incompatibles con el Derecho comunitario, la sección tributaria del Tribunal de Casación, aun siendo en este caso pacífica la necesidad de no aplicar la norma del art. 2946 del Código Civil, ha querido interrogarse sobre la improbable naturaleza de los controlimiti de la norma en cuestión, que prevé un tiempo de limitación. Y ha aprovechado la ocasión para afirmar que «la teoría de los controlimiti encontraba razonables justificaciones en los años setenta y ochenta del siglo pasado [...] hoy parece en plena contradicción con el concepto mismo de integración [...] al punto que el conflicto entre Derecho comunitario y estatal no parece concebible en un espacio jurídico europeo verdaderamente integrado» (Cass. sez. trib. n. 23418 de 2010; en términos, id. n. 7659 de 2012).

\section{LOS CONTROLIMITI DESPUÉS DEL TRATADO DE LISBOA}

Se puede ciertamente sostener que, después de la adopción del Tratado de Lisboa, se ha verificado una verdadera y propia «comunitarización de los controlimiti». De hecho, dice expresamente el nuevo art. 4, párrafo 2, TUE que «la Unión respetará la igualdad de los Estados miembros ante los Tratados, así como su identidad nacional, inherente a las estructuras fundamentales políticas y constitucionales de éstos, también en lo referente a la autonomía local y regional». Mientras el art. 53 de la Carta de Derechos de Niza, que después de Lisboa tiene valor jurídicamente vinculante (tiene el mismo valor jurídico que los tratados), dice que «ninguna de las disposiciones de la presente Carta podrá interpretarse como limitativa o lesiva de los derechos humanos y libertades fundamentales reconocidos, en su respectivo ámbito de aplicación, por el Derecho de la Unión, el Derecho internacional y los convenios internacionales de los que son parte la Unión o todos los Estados miembros, y en particular el Convenio Europeo para la Protección de los Derechos Humanos y de las Libertades Fundamentales, así como por las Constituciones de los Estados miembros». 
Por otra parte, estas importantes innovaciones normativas no hacen sino fotografiar la realidad de las cosas que ya tenía antes de la entrada en vigor del Tratado de Lisboa (es suficiente citar a este propósito, por todas, la sentencia Omega del Tribunal de Justicia comunitario de 11 octubre 2004, en causa C-36/02, en la cual la garantía de la libre prestación de los servicios se oponía a la tutela de la dignidad humana). Pero éstas sirven ciertamente para reiterar cómo es que en el día de hoy no tenga probablemente ningún sentido hablar de controlimiti en la manera en la cual hasta ahora se ha hablado.

En este contexto, tiene una particular relevancia también la firme posición adoptada por el Tribunal de Justicia sobre la cuestión de los controlimiti con el pronunciamiento de la sentencia Melloni (26 de febrero de 2013). Para responder a una petición de decisión prejudicial presentada por el Tribunal Constitucional español, que basaba su razonamiento en la asunción de que «el art. 53 de la Carta autoriza de forma general que un Estado miembro aplique el estándar de protección de los derechos fundamentales garantizados por su Constitución cuando sea más elevado que el derivado de la Carta, y oponerlo en su caso a la aplicación de disposiciones del Derecho de la Unión», el Tribunal de Justicia ha precisado explícitamente que «no puede acogerse esa interpretación» por el motivo que «dicha interpretación del art. 53 de la Carta menoscabaría el principio de primacía del Derecho de la Unión, ya que permitiría que un Estado miembro pusiera obstáculos a la aplicación de actos del Derecho de la Unión plenamente conformes con la Carta, si no respetaran los derechos fundamentales garantizados por la Constitución de ese Estado» (Tribunal de Justicia, 26 de febrero de 2013, C-399/11, apartados 56, 57 y 58).

Por lo tanto, surge una vez más en este punto, y con mayor fuerza, la cuestión de si sería conveniente y necesaria la introducción, en nuestra Constitución nacional, de una disposición específica sobre la Unión Europea. Ya que la disposición del art. 117 de la Constitución italiana —en su forma enmendada en 2001 — sin duda no ha resuelto el problema.

En mi opinión, una disposición constitucional específica sobre la Unión Europea sería realmente útil sólo si fuera de contenido adecuado para permitir superar, de una vez por todas, los debates internos sobre la relación entre los sistemas jurídicos (entre la separación y la integración), así como el interminable debate sobre el sentido y el significado de los controlimiti. Si fuera, por lo tanto, una «Europa-Klausel» que permitiese una mayor apertura de nuestra Constitución, en la perspectiva del «Verfassungsverbund» que defendió la doctrina más avanzada. Con pleno conocimiento 
de que la europeización de las Constituciones nacionales es, de hecho, el único instrumento adecuado para frenar la erosión.

\section{CONCLUSIONES}

En conclusión, es importante reiterar cómo, en el día de hoy, ya no tiene probablemente ningún sentido hablar de controlimiti en la manera en la cual hasta ahora se ha hablado. Mucho más porque la teoría de los controlimiti había nacido con una ambivalencia de fondo. De hecho, si, por un lado, los controlimiti han nacido como instrumento puesto a tutela de las prerrogativas del ordenamiento nacional, por otro, este instrumento ha servido, en cambio, para considerar aceptable el reconocimiento de la primacía del Derecho comunitario, incluso sobre las normas constitucionales. En fin, hay que resaltar que en los más recientes desarrollos de la teoría de los controlimiti — como hemos visto - se advierte una aplicación por parte de aquellos jueces comunes que se muestran favorables a una aplicación difusa/generalizada de los controlimiti, en contraste con lo expresamente reiterado por el Tribunal Constitucional italiano, también en la orden n. 454 de 28 diciembre 2006, con la cual ha excluido expresamente la posibilidad de una aplicación generalizada de los controlimiti por parte del juez común. En realidad, el resultado de la aplicación de la teoría de los controlimiti por parte de los jueces comunes, sin pasar a través del filtro del Tribunal Constitucional, es que los jueces comunes sustituyen/reemplazan a este último en la relación con el Tribunal Europeo de Justicia, impidiendo así al Tribunal Constitucional proseguir el diálogo tan provechosamente trabajado en el curso de los últimos decenios. Por lo tanto, el juez común, a través de la aplicación directa de la teoría de los controlimiti, parece desvelar claramente su indisimulada ambición de sustituir al juez constitucional, convirtiéndose así en el actor principal del diálogo entre tribunales.

\section{REFERENCIAS DOCTRINALES ESENCIALES (EN ORDEN CRONOLÓGICO INVERSO)}

\section{Sobre la protección de los derechos fundamentales en la UE}

Jürgen SchWARZE (ed.), «Grundrechte der Person im Europäischen Gemeinschaftsrechts», en Europarecht. Strukturen, Dimensionen und Wan- 
dlungen des Rechts der Europäischen Union. Augewählte Beiträge, BadenBaden, Nomos, 2012, pp. 373 y ss.; íD., «Der Schutz der Grundrechte durch den EuGH», Neue Juristische Wochenschrift, vol. 58, núm. 48, 2005, pp. 413 y ss.; Ricardo Alonso García, Sistema jurídico de la Unión Europea, 3. ${ }^{a}$ ed., Cizur Menor (Navarra), Thomson Reuters, 2012, pp. 261 y ss.; Damian Chalmers, Gareth Davies y Giorgio Monti, European Union Law, 2. ${ }^{a}$ ed., Cambridge, Cambridge University Press, 2010, pp. 228 y ss.; Thomas VON DANWITZ, «Über die Integrationsverantwortung des Gerichtshofes der Europäischen Union», en Das Europäische Verwaltungsrecht in der Konsolidierungsphase. Die Verwaltung, Beiheft 10, 2010, pp. 241 y ss.; Luigi DANIELE, «La protezione dei diritti fondamentali nell'Unione europea dopo il Trattato di Lisbona: un quadro d'insieme», Dir. un. eur., 2009, pp. 652 y ss.; Giuseppe MoRBIDELLI, «Corte Costituzionale e Corti Europee: la tutela dei diritti (dal punto di vista della Corte di Lussemburgo)», en Diritto processuale amministrativo, núm. 2, 2006, pp. 285 y ss.; Antonio Tizzano, «I diritti fondamentali e le Corti in Europa», en Il diritto dell'Unione Europea, núm. 4, 2005, pp. 839 y ss., y Benedetto CONFORTI, «Note sui rapporti tra diritto comunitario e diritto europeo dei diritti fondamentali», Riv. internaz. dir. uomo, 2000, pp. 423 y ss.

\section{Sobre el impacto de la legislación de la UE en el sistema de fuentes nacionales y de la teoría de controlimiti}

Mario P. Chiтi, Diritto amministrativo europeo, Milano, Giuffré, 2011, pp. 98 y ss.; Antonio TizZANo, «Der italienische Verfassungsgerichtshof (Corte Costituzionale) und der Gerichtshof der Europäischen Union», en Europäische Grundrechte Zeitschrift, 2010, pp. 1 y ss.; Giuseppe Tesauro, «Costituzione e norme esterne», Il Diritto dell'Unione europea, núm. 2, 2009, pp. 195 y ss.; Roberto CHIEPPA, «Nuove prospettive per il controllo di compatibilità comunitaria da parte della Corte Costituzionale», en $\mathrm{Il}$ diritto dell'Unione europea, núm. 3, 2007, pp. 493 y ss.; Guido GRECO, «I rapporti tra ordinamento comunitario e nazionale», en Mario P. CHiтा y Guido GreCo (eds.), Trattato di diritto amministrativo europeo, 2." ed., Milano, Giuffré, 2007, parte generale, vol. II, pp. 827 y ss.; Antonio BARO$\mathrm{NE}$, «A proposito della sentenza Federfarma: fra tutela del consumatore e tutela costituzionale dei diritti fondamentali il Consiglio di Stato smarrisce la retta via?», Il diritto dell'Unione europea, 2006, pp. 201 y ss.; Luigi DANIELE, «La protection des droits fondamentaux peut-elle limiter la pri- 
mauté du droit communautaire et l'obligation de renvoi prejudiciel», en Cabiers de droit européen, 2006, pp. 67 y ss.; Alfonso CELOTTO, «I controlimiti presi sul serio», en http://www.giustamm.it, 7-8, 2005; Giuseppe MorbideLLI, «Controlimiti o contro la pregiudiziale comunitaria?», en Giurisprudenza costituzionale, 2005, pp. 3404 y ss.; Diana-Urania GALETTA, «La previsione di cui all'articolo 3, comma 1, cpv. 1, della legge di revisione del titolo $\mathrm{V}$ della costituzione come definitivo superamento della teoria dualista degli ordinamenti», en E. De Marco y Paola Bilancia (eds.), Problemi del federalismo, Milano, Giuffré, 2001, pp. 293 y ss.; Ingolf PernicE, Kompetenzabgrenzung im Europäischen Verfassungsverbund, Berlin, Humboldt-Universität, 2000, y Alfonso CELOTTO, «Le "modalità" di prevalenza delle norme comunitarie sulle norme interne: spunti ricostruttivi», Rivista italiana di diritto pubblico comunitario, núm. 6, 1999, pp. 1473 y ss. 